\title{
ANALISIS KOMPARATIF PENDAPATAN PETANI PADI PENERIMA BANTUAN MODAL PUAP (PENGEMBANGAN USAHA AGRIBISNIS PERDESAAN) DAN PETANI NON PENERIMA BANTUAN MODAL PUAP DI DESA NGARAK KECAMATAN MANDOR KABUPATEN LANDAK
}

\author{
Sisilia"), Marisi Aritonang ${ }^{2)}$, dan Dewi Kurniati ${ }^{2)}$ \\ 1) Mahasiswa Fakultas Pertanian Universitas Tanjungpura Pontianak \\ 2) Dosen Fakultas Pertanian Universitas Tanjungpura Pontianak
}

\begin{abstract}
In general, the problem of poverty is closely linked to agricultural problems in Indonesia. The worst problem for most Indonesian farmer with limited capital is owned by the farmer. In order to overcome these problems, program Pengembangan Usaha Agribisnis Perdesaan (PUAP). PUAP was one of agriculture in West Kalimantan, especially in the Landak District where have been implemented with the funds as much as Rp.100.000.000,00.- For every poor village or famers federation (Gapoktan). One of the districts that have received the Desa Mandor of the PUAP funding are which is the potential for the development of rice plants, especially in the Desa Ngarak. The PUAP grants distribution were through farmers group federation (Gapoktan) of the certain village.

This study aims to analyze the ratio of the average income of rice farmers PUAP and the average income of farmers in Desa Ngarak non PUAP District Mandor Porcupine District. This study aims to analyze the ratio of the average income of rice farmers PUAP and the average income of farmers in the Desa Ngarak non PUAP Sub District Overseer Landak. The Results of data analysis from this study showed the average income of PUAP farmers amounted Rp.16.754.637/Th/Ha, and the average non PUAP farmers income amounted Rp.13.037.452/Th/Ha. The results showed there were differences in the average income of rice farmers PUAP with an average income of rice farmers non PUAP. Where PUAP program has succeeded in increasing significantly the income of rice farmers in the village Ngarak
\end{abstract}

Keywords: Program PUAP, comparative analysis, income rice farmers 


\section{PENDAHULUAN}

Masalah kemiskinan berhubungan erat dengan permasalahan pertanian di Indonesia. Menurut Hakim (2008), beberapa masalah pertanian yang dimaksud yaitu pertama, sebagian besar petani Indonesia sulit untuk mengadopsi teknologi sederhana untuk meningkatkan produktivitas hasil pertaniannya. Kedua, petani mengalami keterbatasan pada akses informasi pertanian baik harga produksi, harga faktor produksi maupun pasar dan peluang pasar. Ketiga, petani memiliki kendala atas sumber daya manusia yang dimiliki. Keempat, masalah paling dasar bagi sebagian besar petani Indonesia adalah masalah keterbatasan modal yang dimiliki oleh para petani. Masalah modal tersebut diantaranya adalah sebagian besar petani mengalami kekurangan modal untuk berusaha dan memenuhi kebutuhan hidupnya, belum adanya asuransi pertanian, masih adanya praktek sistem ijon dan sistem perbankan yang kurang peduli kepada petani. Salah satu cara untuk menanggulangi permasalahan tersebut, Presiden RI Susilo Bambang Yudoyono telah mencanangkan program Revitalisasi Pertanian pada tanggal 11 Juni 2005 dengan program-program yang salah satunya yaitu program Pengembangan Usaha Agribisnis Perdesaan (PUAP). Melalui keputusan Menteri Pertanian (KEPMENTAN) Nomor 545/Kpts/OT.160/9/2007 dibentuk tim Pengembangan Usaha Agribisnis Perdesaan (PUAP) (Apriyantono, 2004).

Program PUAP dimulai sejak tahun 2008 yang merupakan program terobosan Departemen Pertanian untuk penanggulangan kemiskinan dan penciptaan lapangan kerja, sekaligus mengurangi kesenjangan pembangunan antar wilayah pusat dan daerah serta antar subsektor. PUAP berbentuk fasilitasi bantuan modal usaha petani anggota baik petani pemilik, petani penggarap, buruh tani maupun rumah tangga tani. Program PUAP memiliki tujuan antara lain: (1) untuk mengurangi tingkat kemiskinan dan pengangguran melalui penumbuhan dan pengembangan kegiatan usaha agribisnis di perdesaan sesuai dengan potensi wilayah. (2) Meningkatkan kemampuan pelaku usaha agribisnis, pengurus Gapoktan, penyuluh dan penyelia mitra tani. (3) Memberdayakan kelembagaan petani dan ekonomi perdesaan untuk pengembangan kegiatan usaha agribisnis. (4) Meningkatkan fungsi kelembagaan ekonomi petani menjadi jejaring atau mitra lembaga keuangan dalam rangka akses kepermodalan (Departemen Pertanian, 2008).

Salah satu provinsi yang memperoleh bantuan PUAP adalah Provinsi Kalimantan Barat, khususnya Kabupaten Landak. Kabupaten Landak termasuk salah satu daerah yang potensial untuk pengembangan tanaman pangan, khususnya tanaman padi. Kabupaten Landak merupakan salah satu lumbung padi di Kalimantan Barat. Saat ini program PUAP di Kabupaten Landak telah dilaksanakan dengan jumlah dana yang diterima sebesar Rp.100.000.000.- untuk setiap desa atau Gapoktan. Salah satu kecamatan yang telah menerima bantuan PUAP adalah Kecamatan Mandor, yang merupakan daerah berpotensi untuk pengembangan tanaman padi terutama di Desa Ngarak. Karena potensi pertanian yang besar sehingga peluang untuk mengembangkan kegiatan agribisnis juga besar, umumnya karena keterbatasn modal, petani tidak bisa bergerak leluasa untuk berkarya, namun dengan adanya bantuan PUAP diharapkan tujuannya untuk menumbuhkembangkan agribisnis dapat tercapai dengan optimal untuk mensejahterakan petani dan keluarganya.

Tujuan dari penelitian ini adalah untuk menganalisis perbandingan rata-rata pendapatan petani padi penerima PUAP dan rata-rata pendapatan petani non penerima PUAP di Desa Ngarak Kecamatan Mandor Kabupaten Landak. 


\section{METODE PENELITIAN}

Penelitian ini dilakukan menggunakan metode survei, yaitu penelitian yang dilakukan untuk memperoleh fakta-fakta dari gejala-gejala dan mencari keterangan secara fakta dari suatu kelompok atau daerah (Nazir, 2005).

Lokasi penelitian dipilih secara sengaja (purposive) yaitu di Desa Ngarak Kecamatan Mandor dengan pertimbangan sebagian besar masyarakatnya adalah petani padi. Populasi dalam penelitian ini adalah seluruh petani padi di Desa Ngarak yang berjumlah 519 Kepala Keluarga (KK), yang tergabung dalam 20 kelompok tani, diantaranya 10 kelompok tani penerima PUAP yang berjumlah 259 petani dan 10 kelompok tani non penerima PUAP yang berjumlah 260 petani.

Menurut Sugiyono (2007) agar ukuran sampel yang diambil representatif maka dihitung dengan menggunakan rumus Slovin dengan presisi $15 \%$, sebagai berikut:

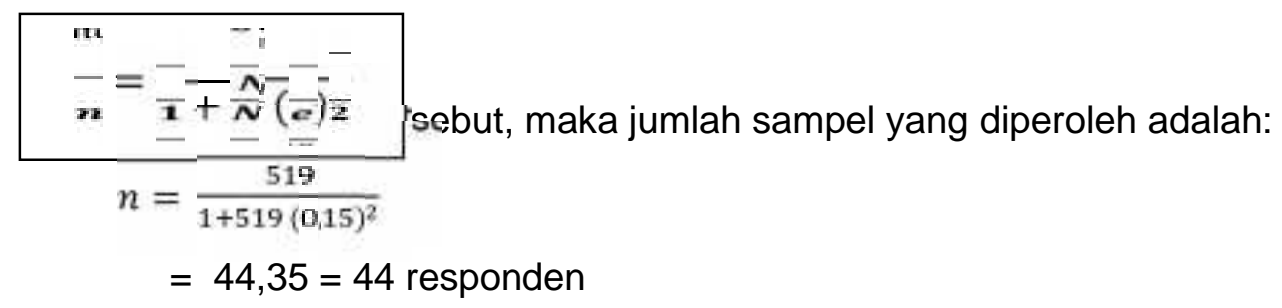

Setelah diperoleh jumlah sampel sebanyak 44 petani, selanjutnya penarikan sampel menggunakan teknik Simple Random Sampling yang dproporsikan sesuai dengan jumlah petani masing-masing kelompok usahatani dengan ketentuan sebagai berikut:

Petani penerima PUAP $=259 / 519 \times 44=21,96=22$

Petani non penerima PUAP $=260 / 519 \times 44=22,04=22$

Dengan demikian, secara proporsional jumlah sampel pada petani penerima PUAP adalah 22 responden dan pada petani non penerima PUAP adalah 22 responden.

\section{ANALISIS DATA}

Untuk mencapai hasil tujuan penelitian dan menguji kebenaran hipotesis digunakan beberapa metode analisis sebagai berikut :

1. Menurut Suratiya (2011), untuk mengetahui pendapatan petani dari hasil usahatani padi yang ada di Desa Ngarak digunakan analisis sebagai berikut :

\section{$\mathbf{I}=\mathbf{T R}-\mathbf{T C}$}

\section{Dimana :}

I = pendapatan usahatani padi (income).

$\mathrm{T}=$ total penerimaan (total revenue) dari usahatani padi.

TC = total biaya (total cost) yang digunakan dalam kegiatan usahatani padi.

2. Menurut Kusnandar (2004), untuk membandingkan tingkat pendapatan petani penerima PUAP dengan non penerima PUAP dilakukan dengan menggunakan uji statistik t-hitung tidak berpasangan (independent) dengan rumus : 


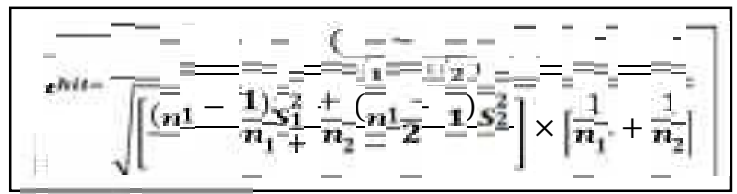

[imman

$\overline{\gamma_{1}}-\overline{1}=$ Nilai rata-rata

$S_{1}^{2}$ dan $\mathrm{S}_{2}^{z}=$ Standar Deviasi

$\mathrm{n}_{1}$ dan $\mathrm{n}_{2}=$ Jumlah sampel

Hipotesis dapat dinyatakan sebagai berikut:

$\mathrm{H}_{0}: \mu_{1}=\mu_{2}$

$\mathrm{H}_{1}: \mu_{1} \neq \mu_{2}$

Dimana:

$\mu_{1}$ : Rata-rata pendapatan usahatani padi petani penerima PUAP.

$\mu_{2}$ : Rata-rata pendapatan usahatani padi petani non penerima PUAP.

Dasar pengambilan keputusan dilakukan dengan membandingkan nilai signifikansi dengan nilai $\alpha(\alpha=0,01)$ yaitu:

$\mathrm{H}_{\mathrm{o}}$ diterima jika sig $>0,01$

$\mathrm{H}_{\mathrm{o}}$ ditolak jika sig $\leq 0,01$

\section{HASIL DAN PEMBAHASAN}

\section{Analisis pendapatan Usahatani Padi}

\section{A. Biaya Produksi}

Biaya produksi yang diteliti dalam penelitian ini terdiri dari biaya variabel dan biaya tetap. Biaya variabel merupakan jenis biaya yang berhubungan langsung dengan besar kecilnya produksi, seperti biaya benih, pupuk, pengolahan lahan dan biaya yang dikeluarkan untuk membayar Tenaga Kerja Luar Keluarga (TKLK). Sedangkan biaya tetap merupakan biaya yang dikeluarkan petani untuk membeli peralatan seperti cangkul, arit, parang dan semprotan dan biaya penyusutan peralatan tersebut. Biaya tetap juga digunakan petani untuk menyewa alat-alat pertanian seperti traktor dan mesin perontok. Rata-rata keseluruhan biaya produksi pada usahatani padi di Desa Ngarak dapat dilihat pada Tabel 1. 
Tabel 1. Rata-rata Biaya Produksi Usahatani Padi Petani Penerima PUAP denganPetani Non PUAP di Desa Ngarak Kecamatan Mandor Kabupaten Landak

\begin{tabular}{|c|c|c|c|c|c|c|c|}
\hline \multirow[t]{2}{*}{ No } & \multirow[t]{2}{*}{ Uraian } & \multicolumn{3}{|c|}{$\begin{array}{c}\text { Petani Penerima PUAP } \\
(\mathrm{Rp} / \mathrm{Ha} / \mathrm{Th})\end{array}$} & \multicolumn{3}{|c|}{$\begin{array}{c}\text { Petani Non Penerima } \\
\text { PUAP (Rp/Ha/Th) }\end{array}$} \\
\hline & & MT1 & MT2 & Jumlah & MT1 & MT2 & Jumlah \\
\hline \multicolumn{8}{|c|}{ 1. Biaya Variabel } \\
\hline & a. Benih & 330.435 & 304.696 & 628.301 & 245.978 & 243.739 & 489.717 \\
\hline & b. Pupuk & 615.761 & 528.348 & 1.131 .806 & 725.378 & 777.878 & 1.144 .109 \\
\hline & c. Pestisida & 210.609 & 155.304 & 361.978 & 236.870 & 210.196 & 447.065 \\
\hline & d. TKLK & 369.565 & 369.565 & 369.565 & 429.348 & 427.174 & 856.522 \\
\hline \multicolumn{8}{|c|}{ 2. Biaya Tetap } \\
\hline & A. Penyusutan & 49.997 & 49.996 & 99.993 & 51.807 & 51.807 & 103.614 \\
\hline & B. Penyewaan & 1.494 .852 & 1.395 .939 & 2.887 .167 & 1.376 .808 & 1.310 .504 & 2.687 .310 \\
\hline & Jumlah & 2.920 .497 & 2.850 .953 & 5.401 .885 & 2.861 .120 & 3.122 .750 & 5.624 .722 \\
\hline
\end{tabular}

Sumber: Analisis Data Primer, 2012

Pada Tabel 1 dapat diketahui bahwa terdapat perbedaan rata-rata biaya produksi antara petani penerima PUAP dan petani non penerima PUAP. Pada penggunaan benih petani penerima PUAP lebih besar daripada petani non penerima PUAP, dikarenakan pada petani penerima PUAP memperoleh tambahan modal dari dana PUAP yang diperoleh dari membeli di kios Gapoktan. Dengan adanya bantuan PUAP para petani dapat memanfaatkan dana tersebut untuk menambah modal usaha, salah satunya adalah pengalokasian untuk meningkatkan produksi padi melalui penambahan jumlah penggunaan benih. Pada penggunaan pupuk juga terjadi perbedaan, hal dikarenakan para petani menggunakan pupuk sesuai dengan kebutuhannya.

Rata-rata biaya pestisida yang dikeluarkan petani non penerima PUAP lebih besar daripada petani penerima PUAP, dikarenakan petani non penerima PUAP lebih banyak menggunakan pestisida, karena tanaman padi petani banyak yang terserang hama, terutama hama kepik hitam, walang sangit dan semut. Para petani juga kurang intensif dalam mengendalikan serangan hama tersebut.

Rata-rata biaya yang dikeluarkan petani penerima PUAP lebih sidikit daripada petani non penerima PUAP karena pada petani penerima PUAP banyak menggunakan tenaga kerja yang berasal dari dalam keluarga, hal ini dapat dilihat dari karakteristik responden pada jumlah anggota keluarga petani penerima PUAP lebih unggul dari petani non penerima PUAP, sehingga dapat mengurangi penggunaan TKLK pada petani penerima PUAP.

Rata-rata biaya penyusutan alat-alat pertanian pada petani penerima PUAP dengan petani non penerima PUAP tidak mengalami perbedaan yang besar, perbedaan nilai penyusutan dari kegiatan usaha tani responden dipengaruhi oleh beberapa hal yaitu: jumlah peralatan yang digunakan, harga beli peralatan, umur ekonomis peralatan, dan intensitas pemakaian peralatan.

Rata-rata biaya penyewaan alat pertanian pada petani penerima PUAP lebih besar dari petani non penerima PUAP, terutama pada penyewaan perontok, karena pada petani penerima PUAP biaya produksinya lebih besar. Pada penyewaan perontok ini dihitung dari banyaknya jumlah per Kg padi yang diperoleh dari usahataninya. 


\section{B. Produksi dan Penerimaan}

Rata-rata produksi padi pada petani penerima PUAP dan petani non penerima PUAP dapat dilihat pada Tabel 2.

Tabel 2. Rata-rata Produksi Usahatani Padi Petani Penerima PUAP dan Petani Non Penerima PUAP di Desa Ngarak Kecamatan Mandor Kabupaten Landak

\begin{tabular}{lcccccccc}
\hline No & Uraian & \multicolumn{2}{c}{$\begin{array}{c}\text { Rata-rata produksi } \\
\mathbf{( K g} / \mathbf{H a})\end{array}$} & $\begin{array}{c}\text { Harga } \\
\text { Gabah } \\
\mathbf{( R p / K g})\end{array}$ & \multicolumn{3}{c}{$\begin{array}{c}\text { Rata-rata penerimaan } \\
\mathbf{( R p / H a )}\end{array}$} \\
& & MT1 & MT2 & Thn & & MT1 & MT2 & Thn \\
\hline 1 & Petani PUAP & 3.048 & 3.443 & 6.491 & 3.000 & 10.391 .304 & 11.765 .217 & 21.918 .280 \\
2 & Petani Non PUAP & 2.957 & 2.944 & 5.648 & 3.000 & 8.910 .870 & 9.751 .304 & 18.662 .174 \\
\hline
\end{tabular}

Sumber: Analisis Data Primer, 2012

Dari Tabel 2 dapat diketahui bahwa rata-rata produksi gabah kering panen pada petani penerima PUAP yaitu sebesar $6.491 \mathrm{~kg} / \mathrm{thn} / \mathrm{ha}$ dan harga jual gabah kering panen sebesar Rp. 3000/kg sehingga total rata-rata penerimaan dari produksi padi adalah sebesar Rp. 21.918.280/th/ha. Sedangkan untuk petani padi non penerima PUAP jumlah hasil produksi padi yang diperoleh petani responden yaitu sebesar $5.623 \mathrm{~kg} / \mathrm{th} / \mathrm{ha}$ dan harga jual gabah kering panen sama dengan petani padi penerima PUAP yaitu sebesar Rp. 3000/kg dengan total penerimaan sebesar Rp.18.662.174/th/ha. Hasil wawancara dengan petani adanya perbedaan tinggi rendahnya produksi dikarenakan bahwa dengan adanya bantuan PUAP para petani dapat memanfaatkan dana tersebut untuk penambahan jumlah penggunaan benih, sehingga dapat meningkatkan produksi. Hal lain yang menyebabkan produksi petani non penerima PUAP rendah yaitu tanaman padi petani banyak terserang hama sehingga produksi yang dihasilkan sedikit.

\section{Pendapatan Petani}

Ukuran yang digunakan untuk mengukur pendapatan petani padi adalah pendapatan bersih. Pendapatan bersih adalah selisih antara penerimaan total petani dengan total biaya yang dikeluarkan oleh petani (Soekartawi, 1995). Sedangkan biaya produksi yang dimaksud dalam penelitian ini adalah semua biaya riil yang dikeluarkan petani selama proses produksi berlangsung. Adapun biaya produksi dalam penelitian ini yaitu biaya tetap dan biaya tidak tetap. Rata-rata pendapatan usahatani padi petani penerima PUAP dan petani non penerima PUAP dapat dilihat pada Tabel 3. 
Tabel 3. Rata-rata Pendapatan Usahatani Padi Petani Penerima PUAP dan Petani Non Penerima PUAP di Desa Ngarak Kecamatan Mandor Kabupaten Landak

\begin{tabular}{|c|c|c|c|c|c|c|c|}
\hline \multirow[t]{2}{*}{ No } & \multirow[t]{2}{*}{ Uraian } & \multicolumn{3}{|c|}{$\begin{array}{c}\text { Petani Penerima PUAP } \\
(\mathrm{Rp} / \mathrm{Ha} / \mathrm{Th})\end{array}$} & \multicolumn{3}{|c|}{$\begin{array}{l}\text { Petani Non Penerima PUAP } \\
\qquad(\mathrm{Rp} / \mathrm{Ha} / \mathrm{Th})\end{array}$} \\
\hline & & MT1 & MT2 & Jumlah & MT1 & MT2 & Jumlah \\
\hline 1 & Penerimaan UT & 10.391 .304 & 11.765 .217 & 21.918 .280 & 8.910 .870 & 9.751 .304 & 18.662 .174 \\
\hline \multirow[t]{3}{*}{2} & Biaya Usahatani & - & - & - & - & 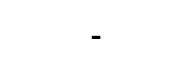 & - \\
\hline & a. Biaya Variabel & 1.526 .370 & 1.357 .913 & 2.491 .650 & 1.637 .574 & 1.658 .987 & 2.937 .413 \\
\hline & b. Biaya Tetap & 1.395 .939 & 1.494 .852 & 2.887 .167 & 1.310 .504 & 1.376 .808 & 2.687 .310 \\
\hline 3 & $\begin{array}{l}\text { Pengeluaran UT } \\
\text { Pendapatan }\end{array}$ & 2.894 .758 & 2.876 .692 & 5.401 .885 & 2.858 .881 & 3.124 .989 & 5.624 .722 \\
\hline 4 & Bersih & 8.844 .721 & 7.540 .351 & 16.754 .637 & 6.890 .637 & 5.788 .119 & 13.037 .452 \\
\hline
\end{tabular}

Sumber: Analisis Data Primer, 2012

Pada Tabel 3 diketahui bahwa total rata-rata pendapatan petani penerima PUAP lebih besar daripada petani non penerima PUAP yaitu sebesar Rp.16.754.637/Th/Ha, sedangkan pendapatan petani non penerima PUAP sebesar Rp.13.037.452/Th/Ha. Dapat diketahui bahwa setelah adanya bantuan PUAP terjadi peningkatan sebesar $57,52 \%$. Persentase tersebut belum cukup untuk menunjukkan bahwa terdapat perbedaan secara nyata pada tingkat pendapatan petani penerima PUAP dan petani non penerima PUAP. Oleh karena itu dalam penelitian ini dilakukan uji statistik t-hitung independent.

Hasil pengujian t-hitung terhadap pendapatan usahatani atas biaya riil para responden yaitu petani penerima PUAP dan petani non penerima PUAP, diperoleh bahwa ada perbedaan nyata terhadap pendapatan usahatani pada petani penerima PUAP dengan petani non penerima PUAP, hal ini berarti rata-rata pendapatan petani yang diperoleh dari usahatani padi penerima PUAP lebih besar daripada pendapatan petani yang diperoleh dari usahatani padi non penerima PUAP.

Banyak faktor yang menyebabkan perbedaan pendapatan antara petani penerima PUAP dan petani non penerima PUAP, yaitu: Petani penerima PUAP mendapatkan kemudahan terutama dalam hal pembelian sarana produksi seperti pupuk, benih dan pestisida, sehingga dapat meningkatkan hasil produksi yang akan berpengaruh pada pendapatan.

Rata-rata biaya produksi yang dikeluarkan oleh petani padi non penerima PUAP lebih besar daripada petani penerima PUAP, hal ini dapat dilihat dari biaya penggunaan pupuk, penggunaan pestisida, biaya TKLK dan biaya penyusutan alat yang besar dibandingkan petani penerima PUAP. Pemahaman patani non penerima PUAP yang rendah akan penggunaan faktor produksi seperti penggunaan pestisida yang tidak digunakan secara efisien yang menambah anggaran pengeluaran usahatani.

Petani penerima PUAP dapat lebih meningkatkan kualitas dan mutu produk dalam jumlah yang lebih banyak dari sebelumnya dan dapat memperluas pangsa pasar, sehingga dengan upaya tersebut dapat lebih meningkatkan pendapatan, karena adanya dana bantuan ini, petani yang awalnya kesulitan modal dapat diatasi. Pada petani penerima PUAP memiliki tanggung jawab untuk mengembalikan pinjamannya sehingga mereka lebih bersemangat untuk menjalankan usahataninya. 
Jika dilihat dari karakteristik responden, terlihat petani penerima PUAP memang lebih unggul dibandingkan dengan petani non penerima PUAP khususnya dalam hal tenaga kerja produktif, pada petani penerima PUAP terdapat sebanyak 20 orang (91\%) dari total responden sedangkan pada petani non penerima PUAP sebanyak 18 orang (50\%). Diduga hal ini juga memberi kontribusi pada peningkatan produksi dan pada kenaikan pendapatan petani.

Jumlah anggota keluarga yang ditanggung, terlihat umumnya petani responden memiliki tanggungan keluarga antara 4-5 orang, yakni untuk petani penerima PUAP 12 orang $(50 \%)$ dan petani non penerima PUAP 7 orang $(25 \%)$, dan untuk tanggungan lebih dari 4 orang untuk petani penerima PUAP sebanyak 6 orang $(32 \%)$ dan petani non penerima PUAP sebanyak 5 orang (25\%). Dengan banyaknya jumlah anggota keluarga yang ditanggung pada petani penerima PUAP, dapat memicu kepala keluarga untuk meningkatkan produktivitas karena banyaknya anggota keluarga yang harus dibiayai. Selain itu anggota keluarga ini juga bisa dimanfaatkan sebagai tenaga kerja dalam kegiatan pengelolaan usaha sehingga bisa mendapatkan hasil yang lebih baik dan mengurangi penggunaan tenaga kerja luar keluarga sehingga dapat mengurangi pengeluaran petani.

Salah satu tujuan utama yang terkait dengan pelaksanaan program PUAP adalah untuk meningkatkan kesejahteraan petani yang dinilai dari peningkatan pendapatan petani. Dari hasil penelitian dengan melakukan wawancara kepada ketua Gapoktan dan petani responden, terutama pada petani penerima PUAP menunjukkan bahwa telah terjadi perubahan peningkatan pendapatan setelah adanya bantuan PUAP. Para petani penerima PUAP juga membayar pinjaman dengan tepat waktu yaitu setelah akhir panen, kemampuan para petani penerima PUAP dalam mengembalikan pinjaman tersebut telah menunjukkan bahwa mereka memiliki kemampuan dalam mengatur keuangan usaha dan keluarga, hal tersebut merupakan potensi yang perlu ditingkatkan dan dijadikan dasar agar program PUAP di masa mendatang dapat terus dilaksanakan dan ditingkatkan.

\section{KESIMPULAN}

Berdasarkan uraian hasil penelitian maupun pembahasan, maka dapat diperoleh kseimpulan sebagai berikut:

1. Rata-rata pendapatan usahatani padi petani penerima PUAP adalah sebesar Rp.16.754.637/Th/Ha, sedangkan pendapatan petani non penerima PUAP sebesar Rp.13.037.452/Th/Ha.

2. Dari hasil analisis uji-t dapat disimpulkan bahwa terdapat perbedaan rata-rata pendapatan petani padi penerima PUAP dengan rata-rata pendapatan petani padi non penerima PUAP. Dimana program PUAP telah berhasil meningkatkan pendapatan petani padi di Desa Ngarak.

\section{SARAN}

Berdasarkan hasil penelitian ini, saran yang dapat disampaikan sebagai berikut :

1. Petani harus aktif dalam keorganisasian agar memperoleh informasi-informasi yang diberikan oleh PPL dan melaksanakan anjuran-anjuran yang diberikan oleh PPL, baik dalam penggunaan pupuk, benih dan pestisida yang sesuai dengan anjuran.

2. Ketua Gapoktan harus menjalin hubungan yang baik dengan semua anggota Gapoktan, terutama kepada para petani yang belum menerima bantuan PUAP, agar dapat mensosialisasikan manfaat dari bantuan PUAP tersebut bagi mereka. 
3. Perlu ditambah lagi anggota penyuluh pertanian lapangan, karena peran dari PPL sangat diperlukan untuk memberikan masukan dan pengawasan terhadap pelaksanaan program PUAP, penyuluh pendamping memiliki peran penting dalam menghubungkan dan mentransfer baik ilmu, teknologi baru hingga pada pemberian pelatihan untuk meningkatkan keterampilan para petani.

4. Pemanfaatan teknologi pertanian juga merupakan langkah yang tepat untuk memacu peningkatan produksi tanaman padi. Petani harus menggunakan pupuk organik, karena pupuk ini lebih sehat untuk tanah dan juga menghemat biaya karena bahannya sudah ada di lapangan, seperti kotoran ternak atau jerami. Pemanfaatan teknologi lainnya seperti, menggunakan metode SRI (System Of Rice Intensification) pada budidaya padi yang memiliki keunggulan yaitu: hemat air, memulihkan kesehatan tanah dan kesuburan tanah, hemat biaya karena hanya butuh benih $5 \mathrm{~kg} / \mathrm{ha}$, hemat waktu karena waktu panen akan lebih awal serta menghasilkan produksi beras yang sehat rendemen tinggi dan tidak mengandung residu kimia.

5. Pemerintah daerah harus terus memantau perkembangan program PUAP agar tepat sasaran sehingga Program PUAP dapat mencapai hasil yang maksimal dan dapat dirasakan oleh petani yang membutuhkan.

6. Perbaikan untuk Program PUAP ke depannya, yaitu sebaiknya bantuan PUAP digunakan juga untuk pengadaan alat teknologi pertanian. Ketua Gapoktan menggunakan batuan PUAP untuk membeli traktor dan mesin perontok, agar para petani dapat menghemat biaya pengeluaran untuk menyewa alat tersebut, karena dengan tersedianya mesin pertanian ini petani dapat meminjamnya di Gapoktan secara bergiliran.

\section{DAFTAR PUSTAKA}

Departemen Pertanian. 2008. Kebijakan Teknis Program Pengembangan Usaha Agribisnis Perdesaan. Jakarta: Departemen Pertanian RI. Dari: http://www. puap.deptan.go.id/kebijakan teknis.pdf. Diakses Jumat 29 Maret 2012, pukul 21:35.

Kusnandar, Dadan. 2004. Metode Statistik, Madyan Press. Pontianak.

Lukman, Hakim.2008. Kelembagaan dan Kemiskinan Indonesia. Dari: http:www.google.com//kelembagaan//html. Diakses Jumat 29 Maret 2012, pukul 19:05 WIB.

Nazir, M. 2005. Metode Penelitian Sosek. Galia Indonesia. Jakarta

Soekartawi.1995. Ilmu Usahatani. Universitas Indonesia Press. Jakarta.

Sugiyono. 2007. Statistika untuk Penelitian. Penerbit Alfabeta, Bandung.

Suratiya, Ken. 2011. IImu Usahatani. Penebar Swadaya. Jakarta. 